\title{
The Expanding Role of the COX Inhibitor/Opioid Receptor Agonist Combination in the Management of Pain
}

\author{
Giustino Varrassi ${ }^{1,2}\left(\right.$ D Cheng Teng Yeam ${ }^{3} \cdot$ Martina Rekatsina $^{4} \cdot$ Joseph V. Pergolizzi $^{5} \cdot$ Panagiotis Zis $^{6}$. \\ Antonella Paladini ${ }^{7}$
}

Published online: 4 August 2020

(c) The Author(s) 2020

\begin{abstract}
Pain management in both outpatient and inpatient settings demands a multidisciplinary approach entailing medical, physical and psychological therapies. Among these, multimodal analgesic regimens stand out as a promising treatment options. Cyclooxygenase (COX) inhibitor/opioid receptor agonist combinations hold great potential as effective pillars in the multimodal pain management by providing adequate analgesia with fewer safety risks due to COX inhibitors' opioid-sparing effect. Thus, these combinations, either freely or in fixed-dose formulation, offer a feasible option for the prescribing clinicians who seek to maximise therapeutic effect while simultaneously minimise adverse effects. The selection of the appropriate nonsteroidal anti-inflammatory drug (NSAID) and opioid agent at optimal doses is essential. It should be tailored to the patients' analgesic necessities, and his/her gastrointestinal and cardiovascular risk, and potential concurrent aspirin use. Moreover, it should allow for addiction risk and the potential opioid-induced bowel dysfunction and constipation. To ensure an optimal match between the characteristics of the patient and the properties of the chosen medication, and to guide adequate and welltolerated treatment decisions, it is of paramount importance to expand clinicians' knowledge of the currently available COX inhibitor/opioid receptor agonist combinations. This invited narrative review deals with the literature evidence covering the components of multimodal opioid-sparing analgesic regimens. Also, it provides insights into the clinically relevant choice criteria to ensure a patient-tailored analgesia.
\end{abstract}

\section{Introduction}

The burden of pain is heavy and pervasive worldwide, with an estimated $20 \%$ of adults suffering from pain and $10 \%$ receiving a diagnosis of pain every year [1]. Importantly, the Global Burden of Disease Study has indicated pain and pain-related diseases as a primary cause of disability

Giustino Varrassi

giuvarr@gmail.com

1 Paolo Procacci Foundation (PPF), Via Tacito 7, 00193 Rome, Italy

2 World Institute of Pain, Winston-Salem, USA

3 Duke-NUS Medical School, 8 College Road, Singapore 169857, Singapore

4 Moorfields Eye Hospital, London, UK

5 NEMA Research Group, Naples, FL, USA

6 Medical School, University of Cyprus, Nicosia, Cyprus

7 Department MESVA, University of L'Aquila, 67100 L'Aquila, Italy and burden worldwide [2]. A recent European pain study recorded higher rates of pain in women and in people with lower economic status, thus, unveiling the so-called "gender- and income-related pain gap" [3]. Among the European countries, Italy ranked third with a chronic pain prevalence of $27-28 \%$ and a high proportion of untreated people (33\% for both acute and chronic pain) $[4,5]$. Common causes of pain include osteo- and rheumatoid arthritis, surgical interventions, cancer and spinal problems [1].

Pain has a substantial impact on individual's quality of life, which affects the whole of society [6]. Disruption of social relationships, depression, and even suicidal ideation are frequently reported by people suffering from long-lasting chronic pain [1]. Absenteeism and productivity reduction are also commonly associated with the experience of pain, thus, highlighting its burdensome impact of pain from societal and employer perspectives [7].

Despite increased awareness on the clinical implication and its management, pain remains undertreated, with a substantial proportion of patients still experiencing intense suffering $[8,9]$. Owing to pain's complex pathophysiology and 
to its multidimensional nature, a multidisciplinary approach is essential to successfully manage both outpatient and inpatient settings. Pain management in today's practice has progressed to embrace a wide variety of multi-level interventions including medical, physical and psychological therapies, among which multimodal analgesia stands as a promising component $[10,11]$. Therefore, it is of outmost importance to reconcile the burden of pain under-treatment with the mounting evidence supporting the efficacy of multimodal analgesia in a wide range of painful conditions. Although the analgesic choice criteria often rely on the pain type (either being nociceptive or neuropathic) and the underlying mechanisms, there might still be uncertainty on which analgesic intervention may provide optimal pain relief across different patient and clinical settings. In this context, a narrative review of the available literature supporting the contribution of COX inhibitors and opioids to a multimodal analgesia-based treatment may expand the current knowledge of available medications.

This paper discusses the burgeoning potential of COX inhibitor/opioid receptor agonist combinations, which are demonstrated as effective pillars in the multimodal pharmacological pain management. Also, insights on the clinically relevant choice criteria to ensure an appropriate and patienttailored analgesia are provided.

Selection of evidence Papers for consideration for the present review were retrieved by a PubMed search, using different combinations of pertinent keywords (e.g. NSAIDs AND opioids AND multimodal regimen), without any limitations in terms of publication date and language. We searched relevant articles considering publications up to April 2020. Documents from Authors' personal collection of literature could also be considered. Papers were selected for inclusion according to their relevance for the topic, as judged by the Authors.

\section{NSAIDs: Balancing Analgesic Efficacy with Tolerability}

\subsection{NSAID Tolerability Profile}

Owning antipyretic, anti-inflammatory and analgesic properties, NSAIDs are considered the first-line treatment and valuable options for treating painful conditions where inflammation is the hallmark [12]. Nevertheless, NSAIDs encompass a class of compounds that substantially differ in terms of clinical efficacy and safety, considering that the selectivity of COX inhibition contributes to the raising tolerability concerns associated with long-term NSAIDs use [13-16]. Despite the large use of both nonselective (e.g. dexketoprofen, diclofenac, ketoprofen, ibuprofen) and selective COX inhibitors (e.g. celecoxib, etoricoxib) for acute and chronic pain, a broad spectrum of untoward reactions involving gastrointestinal (GI) system, liver, kidney, skin and cardiovascular (CV) system have been reported in patients receiving NSAIDs. Therefore, the physician will need to balance between the benefits of anti-inflammatory and analgesic effects and risks of side effects when prescribing the NSAIDs [15].

\subsubsection{Gastrointestinal}

The GI side effects are ranked as the most common among NSAID-related adverse events (AEs). The most frequent are dyspepsia, heartburn, and abdominal discomfort. The most serious event is peptic ulcer with life-threatening complications of bleeding and perforation [15]. Selective COX2 inhibitors have been reported to have fewer GI adverse effects than nonselective NSAIDs [17-20]. However, further studies reported that GI risk might be strictly correlated to the individual drug and its dose and may be limited by preferring enteric-coated formulations (e.g. ketoprofen lysine salt), non-acidic prodrugs, enantiomers (e.g. dexketoprofen trometamin salt) as well as the co-administration of protonpump inhibitors. Finally, NSAID-induced enteropathy, associated with chronic history of NSAID use, is increasingly recognised as an undesirable effect, although still frequently undiagnosed because of its nonspecific signs and symptoms [21]. Overall, increased risk for GI untoward effects is not equally reported across the NSAID class and should be also considered with aspirin co-administration [19, 20].

\subsubsection{Hepatic}

NSAIDs could be associated with a wide range of hepatic impairment. While the mechanism of liver injury from NSAIDs is not well understood, a recent systematic review assessing randomised controlled trials of both nonselective and selective COX inhibitors found that only three NSAIDs (celecoxib, etoricoxib, and diclofenac) demonstrated clinically significant hepatotoxic evidence. Of note, it has been suggested use of the lowest effective dose while avoiding dispensing the aforementioned NSAIDs as the first-line drug if other safer NSAIDs are available, in order to minimise potential risk of hepatotoxicity from NSAIDs [22].

\subsubsection{Renal}

The renovascular effects of NSAIDs are also well known and include kidney function, fluid and urinary electrolyte excretion. Adequate glomerular filtration rate (GFR) may be dependent on afferent arteriole dilatation mediated by prostaglandins. Under conditions of dehydration or blood loss, or in presence of comorbidities such as congestive heart failure 
and cirrhosis or upon treatment with diuretics, inhibition of prostaglandins by NSAIDs would blunt this compensatory mechanism and decrease GFR; thus, increasing the risk of kidney injury [23]. Interestingly, in conditions of volume expansion or high salt intake, non-selective NSAIDs may elevate blood pressure and worsen pre-existing hypertension [23]. Overall, current evidence suggests that nonspecific NSAIDs and COX-2-selective NSAIDs have a similar incidence of these adverse effects, but vary with the extent of COX-2-COX-1 selectivity and the administered dose of these medicines [24]. To date, massive overdose of NSAIDs under conditions of hypovolaemia may cause renal papillary necrosis [23].

\subsubsection{Hypersensitivity}

Hypersensitivity reactions (e.g. including NSAID-related urticaria and angioedema) have been observed in virtually all NSAIDs regardless of their chemical structure and/or an anti-inflammatory potency. The heteroaryl acetic acid group of NSAIDs (such as naproxen, diclofenac, ibuprofen) seems to carry a higher risk of anaphylactic reactions than other groups. Pyrazolones are the most likely NSAIDs to induce immediate hypersensitivity reactions, while newly developed COX2 selective inhibitors can also induce hypersensitivity reactions, although with a very low incidence, estimated at $0.008 \%$ [25].

\subsubsection{Cardiovascular}

The CV safety of NSAIDs has been studied in recent years in a large number of retrospective and prospective clinical studies and meta-analyses. While the results indicate that cardiotoxicity may be a class effect, the magnitude of the risk is widely variable between individual NSAID drugs [26]. The question of CV safety has a paramount importance in patients with existing serious coronary heart disease (CHD), as their baseline risk of $\mathrm{CV}$ events is increased. It has been proposed that five key variables that may affect the extent of $\mathrm{CV}$ risk associated with NSAIDs are the following: COX-2 selectivity, dose responsivity, plasma half-life, blood pressure and interaction with aspirin [27]. In patients recently hospitalised for serious CHD, naproxen was found to show better cardiovascular safety than diclofenac, ibuprofen, and higher doses of celecoxib and rofecoxib [28]. Acknowledging the previously observed intra-class differences, the risk of hospital admission for heart failure (HF) associated with use of individual NSAIDs has been evaluated. Dexketoprofen, compared to over 20 nonselective NSAIDs and some COX 2 selective NSAIDs, ranked second among those NSAIDs and was associated with the lowest risk of hospital admission for HF [14].
Collectively, the data suggest that, from a cardiologic standpoint, no "safe" NSAID for patients in pain currently exists. Nevertheless, NSAID therapy should always be taken for the least amount of time and at the lowest effective dosage, with a careful evaluation of any sign and symptom of cardiovascular complication (e.g. hypertension, peripheral oedema, renal insufficiency) [29]. Overall, current evidence proposes to tailor the choice of NSAIDs to the GI and CV risks in the patient and to take greater account of the relative contribution of NSAID dosing and to the concurrent aspirin use. Thus, individualised risk stratification should be the clinician's primary consideration when selecting NSAIDs as component of a multimodal treatment approach to pain management.

\subsubsection{Infectious Diseases}

The recent outbreak of coronavirus disease (COVID-19) has rapidly spread worldwide. Improvident declarations have raised questions about whether NSAID use could have an impact on coronavirus disease (COVID-19) symptoms. As stated by both European Medicine Agency (EMA) and Food and Drug Administration (FDA), there is currently no scientific evidence establishing a link between ibuprofen and COVID-19. Pending further research, people taking NSAIDs for other reasons should not stop doing so for fear of increasing their COVID-19 risk [16, 30-32].

\subsection{NSAIDs: Opioid-Sparing Pillars of a Multimodal Therapy for Pain}

Recognising the well-documented analgesic and antiinflammatory efficacy of NSAIDs, current international guidelines recommend the use of oral NSAIDs for a broad spectrum of painful conditions including osteoarthritis (OA) [33, 34], post-operative pain [35] and low back pain $[36,37]$ (Table 1). To date, for the majority of the aforementioned painful conditions, the optimal management requires a comprehensive multimodal approach that entails the use of a variety of analgesic medications and/or techniques combined with non-pharmacological interventions to better target the multiple underlying pain mechanisms [33, 35, 36, 38]. Hence, improved clinical outcomes in pain management can be successfully achieved by combining drugs that act through multiple modes and sites of action to the therapeutic end point, i.e. analgesia. Thus, as a result, patients are expected to experience better pain relief with the fewest side effects [10,39-41]. The concept of multimodal analgesia, proposed as clinical approach in the 1990s, has become more commonplace in clinical practice with the aim of coupling the synergistic and/or additive effects of combining analgesic drugs with the need to limit opioid dosing due to efficacy and/or safety 
Table 1 International guideline recommendations on multimodal analgesia

\begin{tabular}{|c|c|c|}
\hline Society & Pathology & Comments \\
\hline $\begin{array}{l}\text { American College of } \\
\text { Rheumatology/Arthritis } \\
\text { Foundation) [33] }\end{array}$ & $\begin{array}{l}\text { Osteoarthritis of the } \\
\text { hand, hip and knee }\end{array}$ & $\begin{array}{l}\text { The broader impact of OA on these comorbidities is of particular } \\
\text { importance when choosing among treatment options and best addressed } \\
\text { by a multimodal treatment plan, rather than one that is limited to the } \\
\text { prescription of a single medication } \\
\text { Optimal management requires a comprehensive, multimodal approach to } \\
\text { treating patients with hand, hip, and/or knee osteoarthritis offered with } \\
\text { shared decision making }\end{array}$ \\
\hline $\begin{array}{l}\text { American Pain Society, the } \\
\text { American Society of Regional } \\
\text { Anaesthesia and Pain Medicine, and the } \\
\text { American Society of Anaesthesiologists' } \\
\text { Committee on Regional Anaesthesia, } \\
\text { Executive Committee, and Administrative } \\
\text { Council [35] }\end{array}$ & Postoperative pain & $\begin{array}{l}\text { Clinicians should offer multimodal analgesia, or the use of a variety of } \\
\text { analgesic medications and techniques combined with nonpharmaco- } \\
\text { logical interventions for the treatment of postoperative pain in children } \\
\text { and adults (strong recommendation, high-quality evidence) } \\
\text { Clinicians should provide adults and children with acetaminophen and/or } \\
\text { NSAIDs as part of multimodal analgesia for management of postopera- } \\
\text { tive pain in patients without contraindications (strong recommendation, } \\
\text { high-quality evidence) } \\
\text { Evidence supports the use of multimodal regimens in many situations, } \\
\text { although the exact components of effective multimodal care will vary } \\
\text { depending on the patient, setting and surgical procedure }\end{array}$ \\
\hline
\end{tabular}

NSAIDs nonsteroidal anti-inflammatory drugs, $O A$ osteoarthritis

concerns [42]. Multimodal analgesia has several advantages over a single agent alone, which include improved analgesia, shorter hospitalisation times, improved recovery and function [10]. Thus, these benefits provide the evidence supporting current international guideline recommendations for both postoperative and OA pain [33, 35]. Multimodal approach with its opioid-sparing effects achieves similar control of pain with fewer opioids (viz. opioid alone), along with a lower incidence of opioidrelated side effects such as nausea, vomiting, sedation, and pruritus [11, 43, 44].

NSAIDs are not alike in terms of opioid-sparing effect. There are substantial differences within this class of compounds, as reported in a recent review evaluating the ability of individual NSAIDs to lower opioid use within the setting of patient-controlled analgesia. The opioid use was reduced by $17-\sim 50 \%$ with diclofenac, 9-66\% with ketorolac, $22-46 \%$ with ibuprofen, 34-66\% with ketoprofen, 36-50\% with dexketoprofen, $38-41 \%$ with tenoxicam, 36-54\% with lornoxicam, and $\sim 50 \%$ with flurbiprofen [44].

Overall, NSAIDs have the potential to play an important role in reducing opioid requirements in the postoperative setting with the exception of meloxicam and piroxicam. Of note, when similar rates of opioid sparing were observed, pain control duration could be significant different ( 6 vs $24 \mathrm{~h}$ for ketoprofen and dexketoprofen, respectively) [44] thus reinforcing the concept that NSAIDs are not alike.

\section{Opioids}

\subsection{Use of Opioids in Multimodal Pain Combinations}

Opioids are commonly employed for moderate-to-severe pain. For many years, they have been the cornerstone for the management of cancer pain. More recently, their use has been extended to treatment of persistent non-cancer pain. Opioids differ in their pharmacological properties, which may be explained by the interaction with different opioid receptors. Based on their activity on the $\mu$ receptor they are classified as strong (e.g. morphine, oxycodone) or weak (tramadol, codeine) [45, 46]. Substantial differences exist within each sub-class in terms of analgesic efficacy, depending on their affinity for $\mu$ receptor as well as their non-opioid mechanisms of action (tramadol potentiates the descending pain-suppressing system) $[45,47,48]$.

Tramadol has a unique dual mechanism of action (weak opioid receptor agonist and weak noradrenaline and serotonin reuptake inhibitor). It exists as a racemic mixture and offers an interesting alternative to other opioids. In fact, the two complementary synergistic actions (probably a reflection of the actions of the two enantiomers) enhance its analgesic effects and improve its tolerability profile. Tramadol has no relevant effects on $\mathrm{CV}$ and pulmonary parameters. It causes less constipation and opioid-induced bowel dysfunction, along with a low addiction rate $[47,48]$. Head-to-head studies with other weak opioids unveiled subtle differences in analgesic efficacy, and partially in safety profile, that seems to favour tramadol over codeine. Using a third molar extraction pain model, Moore et al. compared two doses of 
tramadol (50 and $100 \mathrm{mg}$ ) to codeine, codeine/aspirin and placebo [49]. Both tramadol doses were found superior to placebo with respect to pain relief and pain intensity scores and for time to re-medication. Tramadol $100 \mathrm{mg}$ provided superior pain relief than that obtained by codeine $60 \mathrm{mg}$. Of note, the combination codeine/aspirin offered better mean SPID scores than tramadol monotherapy. Collectively, these findings suggested that tramadol analgesic efficacy is greater than codeine monotherapy, but inferior to the combination of codeine and paracetamol. Thus, tramadol has been combined with both paracetamol [50] and NSAIDs (diclofenac, dexketoprofen) [39, 51-55]. When compared to codeine/paracetamol combination, was found equally effective in the treatment of low back and OA pain, but it was better tolerated than codeine [56]. In the same study, lower proportion of patients receiving tramadol-containing combination experienced constipation (11\% vs $21 \%)$ and somnolence $(17 \%$ vs $24 \%$ ) while a larger, but non-significant, proportion of patients reporting headache (11\% vs 7\%) [56]. Furthermore, thanks to the lower risk for abuse and depression compared to other opioids, some international guidelines considered tramadol as a "single entity" compared to the other opioids, thus issuing distinct recommendations. As a result, while tramadol was conditionally recommended for patients with knee, hip and hand OA, other opioids are conditionally recommended against in the same group of patients, recognising that they may be used under certain circumstances, particularly when alternatives have been exhausted [33].

Challenges with opioids (e.g. adverse events, misuse and abuse with long-term administration) and the spreading of opioid epidemic have led to a renewed emphasis on opioid-sparing multimodal management of pain. Benefits of an opioid-sparing multimodal therapy encompass greater efficacy with multiple mechanisms of action, less risk of opioid misuse and abuse and fewer safety risks with lower doses [57]. Thus, opioid-sparing strategies can mitigate the undesirable effects of opioids by facilitating the use of the lowest effective dose of opioids. In this regard, combining an oral opioid (such as codeine or tramadol) and a non-opioid (such as paracetamol or NSAIDs), either freely or in fixed dose formulation, offers a plausible option for the prescribing clinicians who seek to maximise therapeutic effect while simultaneously minimising adverse effects.

\section{Fixed Dose Cox-Inhibitor/Opioid Receptor Agonist Combinations}

There is a pharmacologic and practical rationale for using combination therapy to treat pain. Compared with single agents, analgesic combinations offer a potential better match to the underlying pain physiology and thus greater efficacy for managing pain and a reduction of side effects [58]. Further possible advantages of fixed-dose combination (FDC) products include dosing convenience, reduction of pill burden, the potential for greater patient adherence and, in the case of FDC products involving an opioid and a non-opioid agent, opioid-sparing effects and fewer side effects due to the reduced doses of each single substance (Fig. 1) [59, 60].

Currently available FDC indicated for the treatment of moderate-to-severe pain include tramadol/paracetamol, tramadol/diclofenac, codeine/ibuprofen, codeine/paracetamol, oxycodone/paracetamol and tramadol/dexketoprofen (Table 2). The aforementioned FDCs have been extensively evaluated and compared to each other in randomised clinical trials [50, 52, 56, 61]. In patients with postoperative pain, ankle sprain pain or subacute lower back pain, tramadol/ paracetamol analgesic effect was found greater than that of either mono-component and generally similar to that of ibuprofen or the fixed-dose combinations hydrocodone/
Fig. 1 Advantages of fixed dose multimodal combinations in pain management

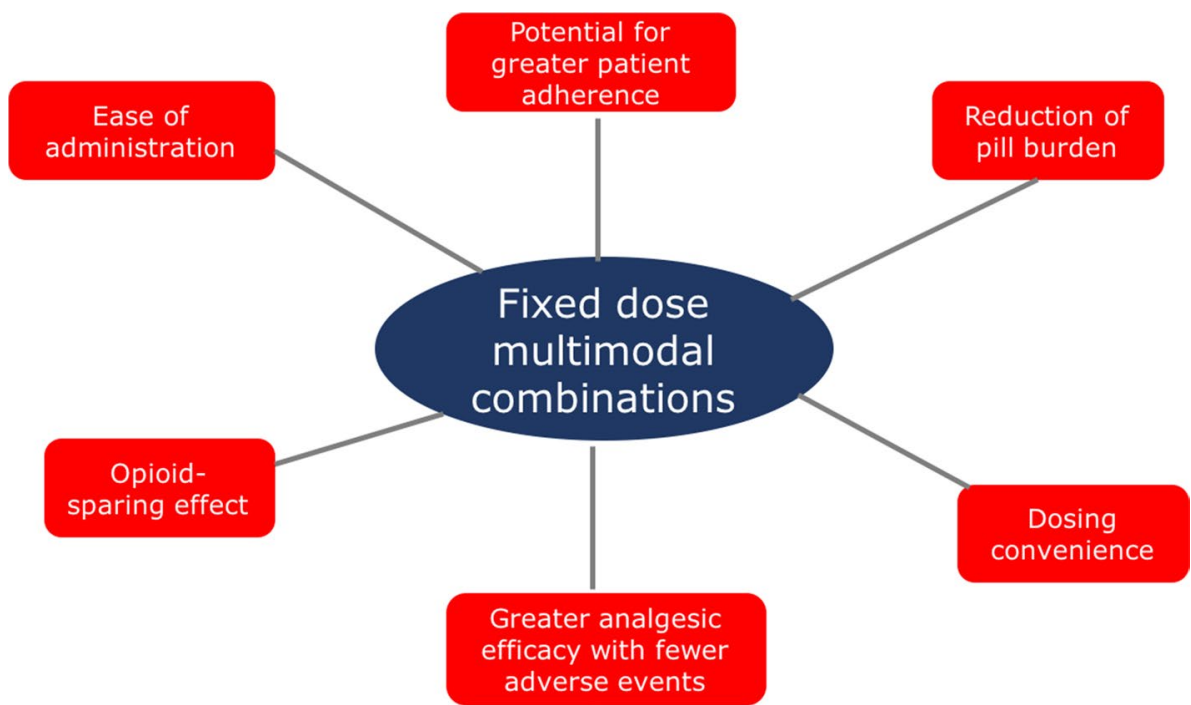


paracetamol, codeine/paracetamol and codeine/paracetamol/ ibuprofen [50]. However, when compared to codeine/paracetamol in postoperative pain after orthopaedic surgery and in OA pain, fewer AEs were observed with lower incidence in constipation, nausea and somnolence, thus underscoring the more favourable safety profile of tramadol versus codeine [56]. Nevertheless, uncertainty remains regarding the chronic adverse effects of paracetamol use, especially at high dosages. Caution should be advised in patients with angina or pre-existing hypertension as well as in patients with a high risk for GI bleeding for paracetamol combined with NSAIDs [62].

Analgesic efficacy of tramadol/paracetamol has been compared to tramadol/diclofenac in a Phase III study conducted in 206 patients with moderate-to-severe pain due to acute musculoskeletal conditions, acute flare of OA or rheumatoid arthritis, or postoperative pain. A greater reduction in pain intensity has been reported in tramadol/diclofenacreceiving patients compared to those treated with tramadol/ paracetamol along with fewer adverse events [52]. These findings have provided earlier evidence supporting the use of tramadol/diclofenac as a treatment option for patients with acute severe pain, although larger and comparative studies are required to definitely position this FDC with respect to other analgesic combinations and to reassure clinicians due to the label warning regarding diclofenac $\mathrm{CV}$ safety [63]. Compared with other NSAIDs, irrespective of COXspecificity, diclofenac shows greater inhibition of platelet aggregation and acts as a competitive antagonist of thromboxane-prostanoid receptor, signifying potential cardiovascular safety [51]. Although CV safety data have not been reported in clinical trials, caution should be advised when selecting diclofenac as a part of a multimodal opioid-sparing combination in $\mathrm{CV}$ patients. In fact, it has increased risk for atrial fibrillation or flutter, ischaemic stroke, heart failure, myocardial infarction, and cardiac death, even at low doses of diclofenac, as recently reported in nationwide cohort studies [64].

The most recently published head-to-head study involving the latest addition to the armamentarium of analgesic combinations, namely tramadol/dexketoprofen $75 \mathrm{mg} / 25 \mathrm{mg}$ employed tramadol/paracetamol as active comparator [61]. This is one of the largest studies carried out in patients with moderate-to-severe acute pain (nearly 800 enrolled, across five European countries) in the impacted third molar extraction model. Compared to tramadol/paracetamol, tramadol/dexketoprofen showed a greater sustained analgesia, a more rapid onset of action, and a higher proportion of patients rating the study medication from "very good" to "excellent". Fewer patients in this group necessitated rescue medication than those receiving tramadol/paracetamol [61]. Accordingly, tramadol/dexketoprofen provided an analgesic superiority in both primary and all the secondary endpoints when compared with tramadol/paracetamol [61]. It has been proposed that the greater analgesic efficacy of tramadol/dexketoprofen results from the balanced and synergistic combination of central analgesia and an anti-inflammatory action that is substantially lacking with tramadol/ paracetamol combination. This appears particularly important especially in acute and chronic osteo-articular pain, always linked to inflammation [65]. The observed earlier onset of action may be relevant from a patient standpoint as it may contribute to the first meaningful perception of pain relief achieved by a higher proportion of patients receiving

Table 2 Overview of available COX inhibitor/opioid receptor agonist FDC

\begin{tabular}{lllll}
\hline Fixed-dose combination & Opioid receptor agonist & COX inhibitor & Available strengths & Available formulations \\
\hline Tramadol/paracetamol & Tramadol & Paracetamol & $37.5 / 325 \mathrm{mg}$ & Film-coated tablet, effervescent \\
& & & $75 / 650 \mathrm{mg}$ & Tablet \\
Tramadol/diclofenac & Tramadol & Diclofenac & $75 / 50 \mathrm{mg}$ & Film-coated tablet \\
Tramadol/dexketoprofen & Tramadol & Dexketoprofen & $75 / 25 \mathrm{mg}$ & Film-coated tablet \\
Codeine/ibuprofen & Codeine & Ibuprofen & $12.8 / 200^{\mathrm{a}} \mathrm{mg}$ & Tablet, capsule \\
& & & $25.6 / 400 \mathrm{mg}$ & IR and ER tablet \\
Codeine/paracetamol & Codeine & Paracetamol & $30 / 500 \mathrm{mg}$ & $5 / 325 \mathrm{mg}$ \\
Oxycodone/paracetamol & Oxycodone & Paracetamol & $7.5 / 325 \mathrm{mg}$ & $10 / 325 \mathrm{mg}$ \\
\end{tabular}

Tramadol/paracetamol tramadol/dexketoprofen codeine/ibuprofen and codeine/paracetamol are currently marketed in EU; tramadol/diclofenac is currently marketed in India and South America (Ecuador, Colombia, Panama, Guatemala, Honduras, Dominican Republic and El Salvador); oxycodone/paracetamol is currently marketed in Ireland Italy and USA

$E R$ extended release, $F D C$ fixed-dose combination, $I R$ immediate release

${ }^{a}$ Available as over-the-counter medicine 
tramadol/dexketoprofen who were, as a result, less prone to seek rescue medication [61].

Indeed, tramadol/dexketoprofen provides multimodal analgesia via different mechanisms of action in the peripheral and central nervous systems and has shown an analgesic efficacy greater than that achieved by either component in monotherapy in the well-established human pain models of dental pain [53, 61] soft tissue surgery [54] and joint replacement surgery [55]. Overall, these findings add to the mounting evidence, involving more than 2500 patients with moderate-to-severe acute pain, that supports the use of tramadol/dexketoprofen combination in the management of moderate-to-severe postoperative and non-surgical acute pain. Importantly, the safety profile of tramadol/dexketoprofen had been consistently in line with that previously known for the single agents in monotherapy in all the clinical trials performed so far [53-55, 61]. Further studies comparing this FDC to other clinically available COX inhibitor/opioid receptor agonist combinations as well as long-term and real-world studies are expected to yield important information about painful conditions that will benefit most from treatment with this latest analgesic combination. Until this evidence becomes available, consensus statements have been recently developed to provide guidance for its use and support clinicians to identify both patient populations and clinical settings for whom this combination may appear an appropriate and valuable treatment option [66]. The recent Delphi study suggested that, in day-case surgery, tramadol/ dexketoprofen could provide effective and rapid pain management, enabling patients to return more quickly to their normal daily activities, in major abdominal and orthopaedic surgery, tramadol/dexketoprofen has proved to be an effective treatment of moderate-to-severe acute post-operative pain. Of note, it has been proposed as suitable option for mixed types of pain, arising from different body structures (joints, muscles, ligaments, etc.) such as acute articular pain or non-specific low back pain (Table 3) [66].

Ibuprofen/codeine combines two inexpensive compounds with the former endowed with a proven efficacy in relief of acute postoperative pain and the latter characterised by a limited analgesic efficacy when administered alone but able to enhance the efficacy of paracetamol $[67,68]$. It is available as FDC over the counter in some countries. A systematic review has revealed that very limited data suggest that ibuprofen $400 \mathrm{mg}$ plus codeine 25.6 to $60 \mathrm{mg}$ could be better than the same dose of either drug alone [69]. In severe or persistent pain, or both, for which large amounts of codeine are required, caution is advised for potential opioid-related adverse events. For example, respiratory depression is dose-related and may have serious consequences in people without previous experience of opioid use, those who are "extensive metabolisers" (able to convert more of the codeine to morphine than is usual), and the elderly in whom reduced renal function leads to accumulation of active metabolites [69].

Finally, oxycodone/paracetamol has a synergistic mechanism of action, that is useful for moderate-to-severe pain and for non-responders to NSAIDs or paracetamol alone, and has proved to be helpful in pain associated with degenerative diseases, musculoskeletal conditions, OA and cancer [70]. When compared to oxycodone/ibuprofen and hydrocodone/ paracetamol, oxycodone $5 \mathrm{mg}$ /ibuprofen $400 \mathrm{mg}$ provided significantly better analgesia in a dental pain model throughout the 6-h study period, although a higher incidence in nausea and vomiting was observed [71]. Notably, it had lesser analgesic effect than rofecoxib $50 \mathrm{mg}$ in moderate to severe post-operative dental pain [70]. Oxycodone/paracetamol is also available as an extended-release formulation that allows a smaller amount of oxycodone per tablet and offers more steady serum concentrations than do immediate-release products, thus prolonging pain relief and augmenting patient acceptability [72]. Nevertheless, potential for abuse should be acknowledged and concern for paracetamol toxicity and dose limitations should be taken into great consideration when selecting this FDC.

\section{Discussion}

Pain poses a substantial burden across the globe and its high prevalence remains the primary cause of disability in adults [1,2]. Despite the wide availability of effective treatment options, pain remains inadequately or poorly managed, with a significant proportion of patients experiencing

Table 3 Advantages of tramadol/dexketoprofen FDC [66]

The combination offers additional benefits over non-fixed combinations, including ease of administration, reduction of pill burden and improved adherence

The oral route of administration improves patient compliance and adherence to treatment and will be of advantage in the outpatient setting It may be of great value in settings where other single or combined drugs are less efficacious or not well tolerated because of adverse side effects Its use leads to effective and rapid analgesia in moderate-to-severe acute pain, reducing the burden of pain. This in turn may potentially have a positive impact on the psychosocial aspects of acute pain such as psychological vulnerability, stress, higher healthcare utilisation, and reduced labour force participation

$F D C$ fixed dose combination 
moderate-to-severe pain in both outpatient and inpatient settings $[8,9]$. During the last decades, we have witnessed significant advances in our understanding of the pathophysiologic basis in acute pain thus appreciating the multidimensional and multifaceted nature of pain [73]. This emerging evidence paved the way to a multidisciplinary treatment approach for pain management that entails medical, physical and psychological therapies among which the multimodal analgesic regimens stand as promising treatment options $[10,11]$. Thus, clinical use of combinations of analgesic drugs has augmented considerably in the last decades with the aim of achieving greater analgesic efficacy (by targeting multiple modes and sites of action) along with fewer untoward effects, commonly observed due to efficacy and/ or safety concerns. A mounting evidence suggests that the synergy created when multimodal regimens are used to target discrete components of the peripheral and central pain pathways provides effective analgesia at lower opioid dosing, reducing related risk and producing fewer adverse effects $[10,11,58-60]$. Accordingly, international guidelines advocate a multimodal approach for pain management by identifying NSAIDs as an integral part of this treatment approach [33, 35, 74]. Opioid agents, once considered the standard approach to preventing acute postoperative pain, are being replaced by a combination of analgesic drugs with diverse modes of action as part of a multimodal approach.

For an effective analgesic combination, the selection of the appropriate NSAID and opioid agent at optimal doses is essential. This can be attained by freely combining analgesics or with FDCs. The latter is simpler, more convenient to use and more suitable to promote adherence to therapy. The choice of NSAIDs should be tailored to the GI and CV risks of the patient and should take in greater account the differences in opioid-sparing effect within the NSAIDs class and the relative contributions of NSAID dosing and concurrent aspirin use to patient risk profile. As per NSAIDs, opioids are not all alike with significant differences in terms of cardio-pulmonary tolerability, causing GI discomfort and somnolence even with two weak opioids such as codeine and tramadol. Among the clinically available FDC combinations of COX inhibitor and opioid receptor agonist, the most recently marketed, tramadol/dexketoprofen, holds great promise for the multimodal pain management by virtue of the large number of patients treated during both the clinical development programme and post-marketing phase (over 2500), the documented analgesic efficacy in both somatic and visceral pain and the earlier onset of action and sustained duration that have been consistently perceived by patients, thus prolonging the time to rescue medication use [53-55, 61].

We acknowledge that our work has some limitations. It has not focused on specific pain conditions, which could require some systematic revision of the literature. In light of the increasing interest in chronicity of acute pain conditions, the aim would be to soon have such studies published, especially for important pain conditions as in postoperative patients. The existing data are such that would also allow to have a meta-analytic study done for interesting surgeries.

\section{Conclusion}

This narrative review article has focused on the importance of multimodal analgesia, especially in some circumstances, regarding acute and chronic moderate-severe pain conditions. It has focused on the usefulness of FDCs, putting in evidence those that are most recent and recommendable.

Acknowledgements The authors would thank the Section Editor of Drugs for the kind invitation. Moreover, they would thank Content Ed Net, and especially Chiara Degirolamo, Ph.D. for preparing the initial drafted manuscript. This was possible thank to an unconditioned grant of the Menarini Group. The final version has been possible thank to the unconditioned support of the Paolo Procacci Foundation and the NEMA Research Group.

\section{Declarations}

Conflicts of interest GV is Member of several Advisory Boards and Speaking Bureaus. Moreover, he is member of several editorial boards of scientific journal. The other authors do not have conflict of interest to declare, in relation to this paper.

Authorship All the authors have participated to ameliorate the quality of the paper. All of them meet the International Committee of Medical Journal Editors (ICMJE) criteria for authorship of this paper, take the responsibility for the integrity of the work as a whole, and have given their approval for this version to be published.

Ethics approval This article is based on previously conducted studies and does not contain any studies with human participants or animal performed by the authors without a previous Ethics Committee approval.

Consent to participate and consent for publication All the authors have contributed to review and ameliorate the quality of the paper and have reviewed and approved the final draft of the manuscript.

Availability of data and material Not applicable.

Code availability Not applicable.

Open Access This article is licensed under a Creative Commons Attribution-NonCommercial 4.0 International License, which permits any non-commercial use, sharing, adaptation, distribution and reproduction in any medium or format, as long as you give appropriate credit to the original author(s) and the source, provide a link to the Creative Commons licence, and indicate if changes were made. The images or other third party material in this article are included in the article's Creative Commons licence, unless indicated otherwise in a credit line to the material. If material is not included in the article's Creative Commons licence and your intended use is not permitted by statutory regulation or exceeds the permitted use, you will need to obtain permission 
directly from the copyright holder. To view a copy of this licence, visit http://creativecommons.org/licenses/by-nc/4.0/.

\section{References}

1. Goldberg and McGee. Pain as a global public health priority. BMC Public Health. 2011;11:770. https://doi. org/10.1186/1471-2458-11-770.

2. Vos T, Abajobir AA, Abate KH, Abbafati C, Abbas KM, et al. Global, regional, and national incidence, prevalence, and years lived with disability for 328 diseases and injuries for 195 countries, 199-2016: a systematic analysis for the Global Burden of Disease Study 2016. Lancet. 2017;390(10100):1211-59. https:// doi.org/10.1016/S0140-6736(17)32366-8

3. Todd A, McNamara CL, Balaj M, Huijts T, Akhter N, Thomson $\mathrm{K}$, et al. The European epidemic: pain prevalence and socioeconomic inequalities in pain across 19 European countries. Eur J Pain. 2019;23(8):1425-36. https://doi.org/10.1002/ejp.1409.

4. Del Giorno R, Frumento P, Varrassi G, Paladini A, Coaccioli S. Assessment of chronic pain and access to pain therapy: a crosssectional population-based study. J Pain Res. 2017;10:2577-84. https://doi.org/10.2147/JPR.S136292.

5. Latina R, De Marinis MG, Giordano F, Osborn JF, Giannarelli D, Di Biagio E, et al. Epidemiology of Chronic Pain in the Latium Region, Italy: a cross-sectional study on the clinical characteristics of patients attending pain clinics. Pain Manag Nurs. 2019;20:37381. https://doi.org/10.1016/j.pmn.2019.01.005.

6. Langley P, Muller-Schwefe G, Nicolaou A, Liedgens H, Pergolizzi J, Varrassi G. The societal impact of pain in the European Union: health-related quality of life and healthcare resource utilization. $\mathbf{J}$ Med Econ. 2010;13(3):571-81.

7. Langley P, Müller-Schwefe G, Nicolaou A, Liedgens H, Pergolizzi J, Varrassi G. The impact of pain on labor force participation, absenteeism and presenteeism in the European Union. $\mathrm{J}$ Med Econ. 2010;13(4):662-72. https://doi.org/10.3111/13696 998.2010.529379.

8. Mills SEE, Nicolson KP, Smith BH. Chronic pain: a review of its epidemiology and associated factors in population-based studies. Br J Anaesth. 2019;123(2):e273-283. https://doi.org/10.1016/j. bja.2019.03.023.

9. Sinatra R. Causes and consequences of inadequate management of acute pain. Pain Med. 2010;11:1859-71. https://doi.org/10.11 11/j.1526-4637.2010.00983.x.

10. Buvanendran A, Kroin JS. Multimodal analgesia for controlling acute postoperative pain. Curr Opin Anaesthesiol. 2009;22(5):588-93. https://doi.org/10.1097/ACO.0b013e3283 30373a.

11. Bujedo BM, Santos SG, Azpiazu AU, Noriega AR, Salazar DG, Andueza MA. Multimodal analgesia for the management of postoperative pain. In: Racz GB, Noe CE, editors. Pain and treatment. IntechOpen; 2014. https://doi.org/10.5772/57401. Available from: https://www.intechopen.com/books/pain-and-treatment/multi modal-analgesia-for-the-management-of-postoperative-pain. Accessed 28 July 2020.

12. Ong CK, Lirk P, Tan CH, et al. An evidence-based update on nonsteroidal anti-inflammatory drugs. Clin Med Res. 2007;5(1):19_ 34. https://doi.org/10.3121/cmr.2007.698.

13. Varrassi G, Alon E, Bagnasco M, et al. Towards an effective and safe treatment of inflammatory pain: a Delphi-guided expert consensus. Adv Ther. 2019;36(10):2618-37. https://doi.org/10.1007/ s12325-019-01053-x.

14. Arfè A, Scotti L, Vars-Lorenzo C, Nicotra F, Zambon A, Kollhorst B, Schink T, et al. Non-steroidal anti-inflammatory drugs and risk of heart failure in four European countries: nested case-control study. BMJ. 2016;354:i4857. https://doi.org/10.1136/bmj.i4857.

15. Scarpignato C, Lanas A, Blandizzi C, Lems WF, Hermann M, Hunt RH, International NSAID Consensus Group. Safe prescribing of non-steroidal anti-inflammatory drugs in patients with osteoarthritis - an expert consensus addressing benefits as well as gastrointestinal and cardiovascular risks. BMC Med. 2015;13:55. https://doi.org/10.1186/s12916-015-0285-8.

16. Varrassi G, Pergolizzi JV, Dowling P, Paladini A. Ibuprofen safety at the golden anniversary: are all NSAIDs the same? A narrative review. Adv Ther. 2020;37:61-82. https://doi.org/10.1007/s1232 5-019-01144-9.

17. Salvo F, Fourrier-Réglat A, Bazin F, et al. Cardiovascular and gastrointestinal safety of NSAIDs: a systematic review of metaanalyses of randomized clinical trials. Clin Pharmacol Ther. 2011;89:855-66. https://doi.org/10.1038/clpt.2011.45.

18. Scarpignato $\mathrm{C}$, Hunt RH. Nonsteroidal anti-inflammatory drug-related injury to the gastrointestinal tract: clinical picture, pathogenesis, and prevention. Gastroenterol Clin N Am. 2010;39:433-64. https://doi.org/10.1016/j.gtc.2010.08.010.

19. Scheiman JM, Hindley CE. Strategies to optimize treatment with NSAIDs in patients at risk for gastrointestinal and cardiovascular adverse events. Clin Ther. 2010;3284:667-77. https:// doi.org/10.1016/j.clinthera.2010.04.009.

20. Castellsague J, Riera-Guardia N, Calingaert B, et al. Individual NSAIDs and upper gastrointestinal complications: a systematic review and meta-analysis of observational studies (the SOS project). Drug Saf. 2012;35:1127-46. https://doi. org/10.2165/11633470-000000000-00000.

21. Rekatsina M, Paladini A, Cifone MG, et al. Influence of microbiota on NSAID enteropathy: a systematic review of current knowledge and the role of probiotics. Adv Ther. 2020. https:// doi.org/10.1007/s12325-020-01338-6.

22. Sriuttha P, Sirichanchuen B, Permsuwan U. Hepatotoxicity of nonsteroidal anti-inflammatory drugs: a systematic review of randomized controlled trials. Int J Hepatol. 2018;2018:5253623. https://doi.org/10.1155/2018/5253623.

23. Harris RC. COX-2 and the kidney. J Cardiovasc Pharmacol. 2006;47(Suppl 1):S37-S42.

24. Hunt RH, Lanas A, Stichtenoth DO, Scarpignato C. Myths and facts in the use of anti-inflammatory drugs. Ann Med. 2009;41:423-37. https://doi.org/10.1080/07853890902887295.

25. Kowalski ML, Woessner K, Sanak M. Approaches to the diagnosis and management of patients with a history of nonsteroidal anti-inflammatory drug-related urticaria and angioedema. J Allergy Clin Immunol. 2015;136:245-51. https:// doi.org/10.1016/j.jaci.2015.06.021.

26. Varga Z, Sabzwari S, Vargova V. Cardiovascular risk of nonsteroidal anti-inflammatory drugs: an under-recognized public health issue. Cureus. 2017;9(4):e1144. https://doi.org/10.7759/ cureus.1144.

27. Pawlosky N. Cardiovascular risk. Are all NSAIDs alike? Can Pharm J. 2013;146(2):80-3. https://doi.org/10.1177/17151 63513481569.

28. Ray WA, Varas-Lorenzo C, Chung CP, et al. Cardiovascular risks of nonsteroidal anti-inflammatory drugs in patients after hospitalization for serious coronary heart disease. Circ Cardiovasc Qual Outcomes. 2009;2(3):155-63. https://doi. org/10.1161/CIRCOUTCOMES.108.805689.

29. Varrassi G, Pergolizzi J, Peppin JF, Paladini A. Analgesic drugs and cardiovascular safety. In: Govoni S, Politi P, Vanoli E, editors. Brain and heart dynamics. Cham: Springer; 2019. https:// doi.org/10.1007/978-3-319-90305-7_43-1.

30. Varrassi G. Warning against the use of anti-inflammatory medicines to cure COVID-19: building castles in the air. Adv Ther. 2020. https://doi.org/10.1007/s12325-020-01321-1. 
31. EMA gives advice on the use of non-steroidal anti-inflammatories for COVID-19. https://www.ema.europa.eu/en/news/emagives-advice-use-non-steroidal-anti-inflammatories-covid-19. Accessed 1 May 2020.

32. FDA advises patients on use of non-steroidal anti-inflammatory drugs (NSAIDs) for COVID-19. https://www.fda.gov/drugs/ drug-safety-and-availability/fda-advises-patients-use-non-stero idal-anti-inflammatory-drugs-nsaids-covid-19. Accessed 1 May 2020.

33. Kolasinski SL, Neogi T, Hochberg MC, Oatis C, Guyatt G, Block J, et al. 2019 American College of Rheumatology/Arthritis Foundation Guideline for the Management of Osteoarthritis of the Hand, Hip, and Knee. Arthritis Rheumatol. 2020;72(2):220-33. https://doi.org/10.1002/art.41142.

34. Kloppenburg M, Kroon FPB, Blanco FJ, et al. 2018 update of the EULAR recommendations for the management of hand osteoarthritis. Ann Rheum Dis. 2019;78:16-24. https://doi.org/10.1136/ annrheumdis-2018-213826.

35. Chou R, Gordon DB, de Leon-Casasola OA, et al. Management of postoperative pain: a clinical practice guideline from the American Pain Society, the American Society of Regional Anesthesia and Pain Medicine, and the American Society of Anesthesiologists' Committee on Regional Anesthesia, Executive Committee, and Administrative Council. J Pain. 2016;17:131-57. https://doi.org/10.1016/j.jpain.2015.12.008.

36. Qaseem A, Wilt T, McLean RM, Forciea MA, et al. Noninvasive treatments for acute, subacute, and chronic low back pain: a clinical practice guideline from the American College of Physicians. Ann Intern Med. 2017;166(7):514-30. https:// doi.org/10.7326/M16-2367.

37. Oliveira $\mathrm{CB}$, et al. Clinical practice guidelines for the management of non-specific low back pain in primary care: an updated overview. Eur Spine J. 2018;27(11):2791-803. https://doi. org/10.1007/s00586-018-5673-2.

38. Imani F, Varrassi G. Ketamine as adjuvant for acute pain management. Anesth Pain Med. 2019;9(6):e100178. https://doi. org/10.5812/aapm.100178.

39. Varrassi G, et al. Multimodal analgesia in moderate-to-severe pain: a role for a new fixed combination of dexketoprofen and tramadol. Curr Med Res Opin. 2017;33(6):1165-73. https://doi. org/10.1080/03007995.2017.1310092.

40. Raffa RB, Pergolizzi JV Jr, Tallarida RJ. The determination and application of fixed-dose analgesic combinations for treating multimodal pain. J Pain. 2010;11:701-9. https://doi. org/10.1016/j.jpain.2009.12.010.

41. Kehlet H, Dahl JB. The value of "multimodal" or "balanced analgesia" in postoperative pain treatment. Anesthes Analges. 1993;77:1048-56. https://doi.org/10.1213/00000539-19931 1000-00030

42. Schug SA, Garrett WR, Gillespie G. Opioid and non-opioid analgesics. Best Pract Res Clin Anaesthesiol. 2003;17:91-110. https://doi.org/10.1053/bean.2003.0267.

43. Wardhan R, Chelly J. Recent advances in acute pain management: understanding the mechanisms of acute pain, the prescription of opioids, and the role of multimodal pain. F1000Research. 2017;6:2065. https://doi.org/10.12688/f1000resea rch.12286.1.

44. Martinez L, Ekman E, Nakhla N. Perioperative opioid-sparing strategies: utility of conventional NSAIDs in adults. Clin Ther. 2019;41(12):2612-28. https://doi.org/10.1016/j.clint hera.2019.10.002.

45. Inturrisi CE. Clinical pharmacology of opioids for pain. Clin J Pain. 2002;18(4 Suppl):S3-S13. https://doi.org/10.1097/00002 508-200207001-00002.
46. Craig CR, Stitzel RE. Modern pharmacology with clinical application. 6th edition, 2004, Lippincott Williams \& Wilkins. ISBN13: 978-0781737623; ISBN-10: 0781737621.

47. Scott LJ, Perry CM. Tramadol: a review of its use in perioperative pain. Drugs. 2000;60(1):139-76. https://doi.org/10.2165/00003 495-200060010-00008.

48. Vazzana M, Andreani T, Fangueiro J, Faggio C, Silva C, Santini A, et al. Tramadol hydrochloride: pharmacokinetics, pharmacodynamics, adverse side effects, co-administration of drugs and new drug delivery systems. Biomed Pharmacother. 2015;70:234-8. https://doi.org/10.1016/j.biopha.2015.01.022.

49. Moore PA, Crout RJ, Jackson DL, Schneider LG, Graves RW, Bakos L. Tramadol hydrochloride: analgesic efficacy compared with codeine, aspirin with codeine and placebo after dental extraction. J Clin Pharmacol. 1998;38(6):554-60. https://doi. org/10.1002/j.1552-4604.1998.tb05794.x.

50. Dhillon S. Tramadol/paracetamol fixed-dose combination. A review of its use in the management of moderate to severe pain. Clin Drug Investig. 2010;30(10):711-38. https://doi. org/10.2165/11205830-000000000-00000.

51. Shah DD, Sorathia ZH. Tramadol/diclofenac fixed-dose combination: a review of its use in severe acute pain. Pain Ther. 2020. https://doi.org/10.1007/s40122-020-00155-7.

52. Chandanwale AS, Sundar S, Latchoumibady K, Biswas S, Gabhane M, Naik M, Patel K. Efficacy and safety profile of combination of tramadol-diclofenac versus tramadol-paracetamol in patients with acute musculoskeletal conditions, postoperative pain, and acute flare of osteoarthritis and rheumatoid arthritis: a phase III, 5-day open-label study. J Pain Res. 2014;7:455-63. https://doi.org/10.2147/JPR.S67817.

53. Moore RA, Gay-Escoda C, Figueiredo R, Toth-Bagi Z, Dietrich T, Milleri S, et al. Dexketoprofen/tramadol: randomised doubleblind trial and con formation of empirical theory of combination analgesics in acute pain. J Headache Pain. 2015;16:541. https:// doi.org/10.1186/s10194-015-0541-5.

54. Moore RA, McQuay HJ, Tomaszewski J, Raba G, Tutunaru $\mathrm{D}$, Lietuviete N, et al. Dexketoprofen/tramadol $25 \mathrm{mg} / 75 \mathrm{mg}$ : randomised double-blind trial in moderate-to-severe acute pain after abdominal hysterectomy. BMC Anesthesiol. 2016;16:9. https://doi.org/10.1186/s12871-016-0174-5.

55. McQuay HJ, Moore RA, Berta A, Gainutdinovs O, Fülesdi B, Porvaneckas N, et al. Randomized clinical trial of dexketoprofen/tramadol $25 \mathrm{mg} / 75 \mathrm{mg}$ in moderate-to-severe pain after total hip arthroplasty. Br J Anaesthesia. 2016;116:269-76. https:// doi.org/10.1093/bja/aev457.

56. Mullican WS, Lacy JR, TRAMAP-ANAG-006 Study Group. Tramadol/acetaminophen combination tablets and codeine/ acetaminophen combination capsules for the management of chronic pain: a comparative trial. Clin Ther. 2001;23(9):429-45. https://doi.org/10.1016/s0149-2918(01)80118-1.

57. Sullivan D, Lyons M, Montgomery R, Quinlan-Colwell A. Exploring opioid-sparing multimodal analgesia options in trauma: a nursing perspective. J Trauma Nurs. 2016;23(6):36175. https://doi.org/10.1097/JTN.0000000000000250.

58. Raffa RB, Tallarida RJ, Taylor R, Pergolizzi JV. Fixed-dose combinations for emerging treatment of pain. Exp Opin Pharmacother. 2012;13(9):1261-70. https://doi.org/10.1517/14656 566.2012.668531.

59. Raffa RB, Pergolizzi JV, Tallarida RJ. Analgesic combinations. J Pain. 2010;11(8):701-9. https://doi.org/10.1016/j.jpain .2009.12.010

60. Raffa RB, Clark-Vetri R, Tallarida RJ, Wertheimer AI. Combination strategies for pain management. Exp Opin Pharmacother. 2003;4(10):1697-708. https://doi.org/10.1517/14656 566.4.10.1697. 
61. Gay-Escoda C, Hanna M, Montero A, Dietrich T, Milleri S, Giergiel E, et al. Tramadol/dexketoprofen (TRAM/DKP) compared with tramadol/paracetamol in moderate to severe acute pain: results of a randomised, double-blind, placebo and active-controlled, parallel group trial in the impacted third molar extraction pain model (DAVID study). BMJ Open. 2019;9(2):e023715. https://doi.org/10.1136/bmjopen-2018023715 .

62. McCrae JC, Morrison EE, MacIntyre IM, Dear JW, Webb DJ. Long-term adverse effects of paracetamol-a review. Br J Clin Pharmacol. 2018. https://doi.org/10.1111/bcp.13656.

63. European Medicines Agency. New safety advice for diclofenac -CMDh endorses PRAC recommendation [press release]. London: European Medicines Agency; 2013. https://www. ema.europa.eu/ema/index.jsp?curl=pages/news_and_events/ news/2013/06/news_detail_001830.jsp\&mid=WC0b01ac05 $8004 d 5 c 1$. Accessed 20 July 2020.

64. Schmidt M, Sorensen HT, Pedersen L. Diclofenac use and cardiovascular risk: series of nationwide cohort studies. BMJ. 2018;362:k3426. https://doi.org/10.1136/bmj.k3426.

65. Fusco M, Skaper SD, Coaccioli S, Varrassi G, Paladini A. Degenerative joint diseases and neuroinflammation. Pain Pract. 2017;17(4):522-32. https://doi.org/10.1111/papr.12551.

66. Varrassi G, et al. Expert consensus on clinical use of an orally administered dexketoprofen plus tramadol fixed-dose combination in moderate-to-severe acute pain: a Delphi study. Adv Ther. 2019;36(11):3174-85. https://doi.org/10.1007/s12325-019-01053 $-\mathrm{x}$.

67. Toms L, Derry S, Moore RA, McQuay HJ. Single dose oral paracetamol (acetaminophen) with codeine for postoperative pain in adults. Cochrane Database Syst Rev. 2009. https://doi. org/10.1002/14651858.CD001547.pub2.

68. Moore RA, Derry CJ, Derry S, Straube S, McQuay HJ. A conservative method of testing whether combination analgesics produce additive or synergistic effects using evidence from acute pain and migraine. Eur J Pain. 2012;16(4):585-91. https://doi. org/10.1016/j.ejpain.2011.08.009.

69. Derry S, Karlin SM, Moore RA. Single dose oral ibuprofen plus codeine for acute postoperative pain in adults (Review). Cochrane Database Syst Rev. 2015;2:CD010107. https://doi. org/10.1002/14651858.CD010107.pub3.

70. Gatti A, Sabato E, Di Paolo AR, Mammucari M, Sabato AF. Oxycodone/paracetamol a low-dose synergic combination useful in different types of pain. Clin Drug Investig. 2010;30(Suppl 2):3-14.

71. Litkowski LJ, Christensen SE, Adamson DN, van Dyke T, Han S, Newman KB. Analgesic efficacy and tolerability of oxycodone $5 \mathrm{mg} /$ lbuprofen $400 \mathrm{mg}$ compared with those of oxycodone 5 $\mathrm{mg} /$ acetaminophen $325 \mathrm{mg}$ and hydrocodone $7.5 \mathrm{mg} /$ acetaminophen $500 \mathrm{mg}$ in patients with moderate to severe postoperative pain: a randomized, double-blind, placebo-controlled, singledose, parallel-group study in a dental pain model. Clin Therap. 2005;27(4):418-29.

72. Pergolizzi JV, Taylor R Jr, Raffa RB. The potential role of an extended-release, abuse-deterrent oxycodone/acetaminophen fixed-dose combination product for the treatment of acute pain. Adv Ther. 2015;32:485-95.

73. Rekatsina M, Paladini A, Piroli A, Zis P, Pergolizzi JV, Varrassi G. Pathophysiologic approach to pain therapy for complex pain entities: a narrative review. Pain Ther. 2020. https://doi.org/10.1007/ s40122-019-00147-2.

74. Nicosia F, Nolli M, Pagnoni R, Paolicchi A, Rossignoli L, Sansone A, et al. SIAARTI Recommendations for the treatment of postoperative pain. Minerva Anestesiol. 2002;68:735-50. 